\title{
MEMBEDAH MASALAH KEMISKINAN EKONOMI DI INDONESIADARI PERSPEKTIF KARL MARX TENTANG AGAMA SEBAGAI PRODUKS ALIENASI
}

\author{
Ditulis oleh : Dr. I Made Priana
}

\begin{abstract}
This article tries to explore the economic poverty in Indonesia from Karl Marx's perspective that religion is the product of alienation. Critical insight from Karl Marx that religion tends to give comfort to the suffering people by showing them about the happiness in the world after, and not to empower the suffering people to struggle and to overcome the suffering by working hard and working smart, is seemingly constructive. It is said so, since religion has spiritual and social dimention. Even, religion has function to transform that the world where

we live now become the heavenly world. Religion must teach people not to escape from difficulty but to overcome it for a better life in this world. As religious people we not have to dream that we have wings to fly seeking other world. Istead, we have to pray that we present the heavenly world in this world by doing that we are for the poor that they might have a better life.
\end{abstract}

\begin{abstract}
Abstrak
Paper ini meneliti masalah kemiskinan ekonomi di Indonesia dari sudut pandang Karl Marx tentang agama sebagai sumber alienasi. Pemikiran kritis Karl Marx bahwa agama cendrung memberikan penghiburan kepada manusia yang menderita dengan menunjukkan kepada mereka tentang kebahagiaan di dunia akhirat, namun tidak memberdayakan manusia yang menderita itu untuk berjuang dan mengatasi penderitaan melalui kerja keras dan kerja cerdas, nampaknya merupakan sebuah pandangan yang membangun. Hal itu dikatakan demikian, sebab agama memang memiliki dimensi ilahi dan juga sosial. Bahkan agama mempunyai fungsi untuk mentransformasi agar dunia dimana kita hidup sekarang ini, menjadi dunia surgawi. Agama harus mengajar manusia untuk tidak melarikan diri dari kesulitan, tetapi justru untuk mengatasi kesukaran itu demi kehidupan yang lebih baik di dunia ini. Sebagai umat beragama, kita tidak mesti bermimpi agar kita mempunyai sayap untuk bisa terbang mencari dunia yang lain. Sebaliknya, kita harus berdoa dan bekerja untuk menghadirkan dunia surgawi di dunia ini, dengan jalan berpihak kepada sesama yang miskin agar mereka memiliki kehidupan yang lebih baik. Siapa berdoa karena beragama, dia akan berdiri di pihak korban, bukan di pihak pemenang.
\end{abstract}




\section{Pendahuluan}

Secara idealitas Indonesia adalah negeri yang sangat potensial untuk mengantar seluruh anak negeri hidup dalam kesejahteraan ekonomi. Betapa tidak,dari segi geography Indonesia adalah negeri dimana tanah dan airnya,tidak hanya luas tetapi juga sangat subur, dan mengandung banyak kekayaan yang bisa menjamin kelangsungan hidup seluruh anak negri. Oleh karena kesuburannya yang sangat nyata, negeri ini dijuluki sebagai tanah surga dimana tongkat dan batu bisa jadi tanaman. Indonesia adalah negeri kepulauan yang sangat kaya. Melihat kekayaannya yang berlimpah ruah, negeri kepulauan ini dijuluki sebagai negeri berkolam susu dimana ikan dan udang menghampiri anak negeri sehinga kail dan jala akan cukup menghidupi mereka.

Kemudian dari segi sosial politik,Indonesia adalah negeri yang memiliki kontrak sosial berupa idiologi visioner dan konstitusicerdas. Seirama dengan keluhuran idiologinya yakni Pancasila dan keagungan konstitusinya yaitu Undang Undang Dasar 1945, Indonesia berjuluk sebagai negeri yang berbinekha tunggal ika, negeri yang sekalipun berbeda beda suku, ras dan agama tetapi memiliki tujuan satu, yaitu Indonesia setara Indonesia sejahtera.Namun dalam realitas, Indonesia sekalipun memiliki kapital kapital seperti tersebut di atas, dan telah melaksanakan pembangunan nasional selama 70 tahun,masih banyak memiliki penduduk miskin ketimbang yang tidak miskin. Choromaster mengemukakan bahwa prosentase penduduk Indonesia yang miskin sekali 7,5 \%, miskin 38,55 \%, hampir miskin 37,19\% dan tidak miskin 16,69\%1.

\section{Masalah Kemiskinan Ekonomi di Indonesia Dari Perspektif Karl Marx Tentang Agama Sebagai Produks Alienasi.}

Data tentang prosentase penduduk Indonesia miskin seperti tersebut di atas menunjukkan bahwa dalam pembangunan nasional terjadi ketimpangan ekonomi yang sangat tajam pada masyarakat Indonesia. Ketimpangan ini disebabkan oleh ketidakadilan yang dilakukan oleh komponen anak bangsa dalam berekonomi. Dalam kehidupan berekonomi, beberapa komponen anak bangsa, hanya dengan berbekal nilai atau asas kebebasan namun melalaikan nilai kesetaraan, seturut dengan arus dan tatanan globalisasi, menggunakan kemampuan yang ada padanya untuk mendapat sebanyak mungkin harta benda dari sumber sumber penghidupan yang ada di tanah dan air Indonesia. Sembari demikian mereka tidak menghiraukan keberadaan sesamanya yang karena ketidakmampuan, dan juga karena hak kesempatannya untuk memperoleh dirampas, menjadi anak bangsa yang tidak beruntung, dimana mereka tidak bisa menikmati dengan bebas dan cukup, apa yang sebenarnya alam ingin persembahkan baginya.

Cara berekonomi dalam arus dan tatanan kapitalisme yang dilakukan oleh beberapa anak bangsa seperti tersebut di atas, sampai mencipta sebuah fenomena di Bali dan agaknya juga di daerah-daerah Indonesia lainnya, bahwa ada beberapa pantai tidak bisa dipakai lagi oleh masyarakat umum untuk lalulalang, tempat untuk mengail udang dan ikan, apalagi untuk berenang, karena pantai itu kini menjadi view sebuah hotel, sehingga dikemas sedemikian rupa

\footnotetext{
${ }^{1}$.Choromaster, NKRI HARGA MATI ( Yogyakarta : Penerbit Samudra Biru, 2012 ), 73.
} 
seolah-olah pantai itu adalah milik hotel. Dalam hal ini terjadi dominasi pihak yang kuat terhadap pihak yang lemah. Pihak yang bermodal besar menindas kedaulatan sesamanya bahkan mematikan keinginan sesamanya dalam melakukan pengupayaan pendapatan dari alam sebagai sumber penghidupan ${ }^{2}$.Arus globalisasi dan tatanan kapitalisme memperkaya yang kuat dan mempermiskin yang lemah.

Sekalipun arus kapitalisme dan tatanan globalisasi di Indonesia berimplikasi seperti termaksud di atas, pemerintah, pengusaha, politikus, media masa menyambut kapitalisme dan globalisasi dengan gegap gempita. Reaksi yang demikian ini mencerminkan bahwa arus dan tatanan globalisasi cocok dengan selera kebanyakan orang Indonesia. Hal itu nampaknya tentu tidak aneh, sebab manusia secara kodrati adalah makhluk yang akan sangat merasa puas, bila pertama, ia diberi kebebasan untuk mengupayakan apa yang menjadi kebutuhannya, dan kemudian ketika ia diberi kebebasan sesuka hatinya untuk menikmati segala sesuatu yang telah dimilikinya. Setiap orang pada dirinya memiliki kecendrungan untuk bersikap bebas, hedonis dan egois ${ }^{3}$.Pemerintah, politikus dan mas media Indonesia condong mengikuti arus globalisasi dan tatanan kapitalisme, bukan melawannya.

Kehadiran agama di Indonesia sampai sekarang ini lebih berperan sebagai agama bagi orang miskin daripada agama orang miskin. Agama memberi bantuan karitatif kepada orang miskin seperti memberi nasi bungkus kepada yang lapar. Agama melaksanakan pelayanan reformatorik seperti memberi bantuan beasiswa kepada para pelajar yang tidak mampu secara ekonomi. Agama juga melaksanakan pendampingan bagi kaum miskin dalam menghadapi realita kemiskinan tidak dengan memberantas struktur dan sistim yang menyebabkan dan memeliara kemiskinan, melainkan dengan mengarahkan mereka untuk menerima kemiskinan dan menghibur mereka dengan mengajak mereka untuk berkiblat ke dunia yang akan datang.

Agama di Indonesia tidak mengidentifikasi dirinya dengan kaum miskin sehingga agama tidak banyak merasakan apa yang orang miskin rasa dan tidak bisa memperjuangkan pembebasan bagi orang miskin dari struktur dan sistim yang menindas. Agama di Indonesia sibuk untuk mengajak orang miskin menatap sorga dari bumi, dan bukan menancapkan sorga di bumi. Perlakuan agama di Indonesia terhadap orang miskin tidak menolong orang miskin untuk memperoleh apa yang menjadi haknya di bumi yakni hidup berbagi atas apa yang bumi beri bersama dengan sesamanya. Agama di Indonesia membuat orang miskin tidak menjadi insan sebagaimana dia seharusnya menjadi, yaitu menjadi insan yang dengan kemampuannya harus mengatasi masalah masalah penyebab kemiskinan demi kebahagiannya di dunia ini.

Melihat kehadiran dan peran agama di Indonesia seperti terpapar di atas dan dalam rangka berbenah diri agar kita bisa menghadirkan kehidupan beragama yang membebaskan dan mensejahterakan, kita perlu menyimak dan mempertimbangkan apa yang dikatakan oleh Karl Marx bahwa Agama itu adalah produks alienasi. Karl Marx yang berkarier pada pada jaman revolusi industri di Prancis dan Inggris, menyaksikan sendiri kesengsaraan dan kemiskinan para buruh industri yang disebabkan oleh pemerasan dan eksploitasi yang dilakukan oleh para pemilik mesin mesin dan pabrik pabrik dalam industri. Pengalaman pengalaman ini menyebabkan Marx memiliki pandangan yang sangat pesimistis terhadap kapitalisme.Pengalaman dan pandangan Marx yang demikian ini menuntun dia menyusun gagasan agresif yang memiliki implikasi untuk teori sosial dan tindakan politis atas konflikkepentingan yang tampaknya tak terdamaikan yang timbul dalam zaman pemekaran 2004), 83

2. I Nyoman Darma Putra, BALI Menuju Jagaditha : Aneka Perspektif ( Denpasar : Bali Pustaka Post,

3 .Mohammad Takdir Ilahi, Nasionalisme Dalam Bingkai Pluralitas Bangsa, Paradigma Pembangunan \& Kemandirian Bangsa ( Yogyakarta : AR - RUZZ MEDIA, 2012 ), 129. 
kapitalis ini. Gagasan Marx ini adalah sebuah usahanya untuk meningkatkan revolusi sosialis, sehingga kaum proletariat dapat menikmati sebagian besar kelimpahan materiil yang dihasilkan oleh industrialisme ${ }^{4}$.

Inti seluruh teori Marx adalah proposisi bahwa kelangsungan hidup manusia serta pemenuhan kebutuhannya bergantung pada kegiatan produktif dimana secara aktif orang terlibat dalam mengubah lingkungan alamnya. Namun kegiatan produktif itu mempunyai akibat yang yang paradok dan ironis, karena begitu individu mencurahkan tenaga kreatifnya itu dalam kegiatan produktif, maka produk produk dari kegiatan ini memiliki sifat sebagai benda obyektif yang terlepas dari manusia yang membuatnya. Karena kegiatan produktif meliputi penggunaan tenaga manusia dan kemampuan kreatifnya, maka produk produk yang diciptakan itu sebenarnya mewujudkan sebagian dari " hakikat manusia " itu. Jadi bagi Marx, manusia mengkonfrontasikan hakikatnya sendiri dalam bentuk yang sudah terasing atau diasingkan. Manusia mengkonfrontasikan hakikatnya sendiri sebagai benda dalam dunia luar, yang berada di luar jangkauan pengontrolan mereka, dan malah manusia harus menyesuaikan diri dengannya. Dalam teorinya tentang alienasi, Marx berpandangan bahwa, setiap individu harus menyesuaikan diri dengan dunia benda benda yang membatasi kebebaannya sebagai manusia, walaupun sebenarnya manusialah yang menciptakan benda benda itu. Manusia tidak sadar bahwa hambatan hambatan dan kungkungan kungkungan yang menyulitkan mereka adalah ciptaan mereka sendiri ${ }^{5}$.

Teori Marx mengenai alienasi dan pengasingan diri sangat dipengaruhi oleh pembalikan Feuerbach terhadap filsafat Hegel. Bagi Hegel Allah menciptakan dunia dengan sebuah tindakan alienasi diri dan pada akhirnya mempersatukannya kembali kedalam dirinya sendiri. Feuerbach dalam penafsirannya tentang agama, sebagaimana termuat dalam bukunya " The essence of Christianity ", membalikkan gagasan ini dan berpendapat bahwa, manusia menciptakan gagasan tentang Allah, mengaruniaNya dengan sifat sifat manusia yang paling luhur dan kemudian menyembah konsep " terasing " tentang dirinya sendiri. Meskipun teori Marx mengenai alienasi dipengaruhi oleh Feuerbach, Marx juga mengkritik Feuerbach. Khususnya dia menyerang penekanan materialistis Feuerbach yang berat sebelah serta pandangannya yang ahistoris abstrak mengenai individu yang pasif yang terlepas dari konteks sosialnya.

Bertentangan dengan Feuerbach, Marx menekankan pentingnya pemahaman terhadap konteks sosial dan sejarah yang khas, dimana bentuk- bentuk khusus kesadaran dan ilusi ilusi agama muncul. Menurut Karl Marx, agama memang adalah produk alienasi sosial, sebab bertolak dari penderitaan sosial yang menjadi beban manusia, manusia meremehkan kemanusiaanya bahkan akhirnya menciptakan kesadaran falsu dalam dirinya bahwa segala derita sosial adalah sebuah realita. Manusia cendrung untuk memeliara kesadaran palsu ini. Kemudian, Marx juga menyatakan bahwa agama sebagai produk alienasi sosial, condong untuk membujuk manusia menerima realita sosial, lalu menuntun manusia untuk merindukan kebahagiaan di dunia yang akan datang bukan kebahagiaan di dunia sekarang ini ${ }^{6}$.

Marx berkeyakinan bahwa alienasi sosial bisa diatasi. Usul Marx untuk mengatasi alienasi sosial adalah melalui perubahan sosial radikal yaitu manusia bersama sama tidak lagi berteori, namun mengubah kondisi kondisi sosial sehingga kesadaran manusia ditransformasi. Dalam rangka mencipatakan agama sebagai produk dis- alienasi, menurut Marx manusia harus

${ }^{4}$. Wahyu Murtiningsih, Para Filsuf dari Plato samapai Ibnu Bajjah, ( Jogjakarta : IRCiSoD, 2012 ) $155-156$

5 . Gregory Baum, Religion and Alienation, ( New York : Paulist Press, 1975 ),25 - 29.

6 . Gregory Baum, Religion and Alienation, 24. 
semakin dalam memasuki kemanusiaannya dan semakin menghidupkan mimpinya akan keadaan sosial yang lebih humanis.

Bertolak dari kehidupan beragama di Indonesia sebagaimana terpapar di atas, menyimak pandangan Karl Marx tentang agama sebagai produk alienasi, maka introspeksi diri yang patut kita lakukan dalam kehidupan beragama adalah kita harus menjadikan agama sebagai jalan untuk tidak mengajak umat manusia melarikan diri dari persoalan dan derita yang menimpanya. Melainkan justru menolong umat manusia mengembangkan kemampuannya agar dapat berpartisipasi aktif dalam berbagai tindakan penataan struktur yang menghormati kehidupan; bahkan juga perombakan sisitim yang menindas dan menghancurkan kemanusiaan.

Masalah kemiskinan ekonomi di Indonesia tidak akan bisa diselesaiakan bila dalam beragama kita hanya beragama bagi orang miskin. Kita harus menjadikan agama kita sebagai agama orang miskin. Bersama orang miskin kita bergulat memberantas segala penyebab kemiskinan sampai ke akar akarnya. Bersama orang miskin kita terpanggil untuk berpartisipasi aktif dalam berbagai tindakan pentaan struktur yang menghormati kehidupan,bahkan juga perombakan sistim yang menindas dan menghancurkan kemanausiaan. Menjadi agama orang miskin, kita patut memiskinkan diri dalam rangka hidup berbagi. Dalam Alkitab ada narasi bahwa pernah terjadi di suatu hari di Galilea,lima ribu orang yang mendengarkan pengajaran Yesus tidak beranjak dari tempat berlangsungnya pengajaran, tentu karena mereka sangat menikmati pengajaran Yesus. Para murid mengusul kepada Yesus agar orang banyak itu dibubarkan. Usul itu nampaknya dilatari oleh kebiasaan atau sifat para murid yang suka lari dari kesukaran dan tidak menyukai hidup berbagi. Yesus tidak menerima usul itu malah sebaliknya Yesus menegaskan bahwa para murid harus memberi lima ribu orang itu makan ( Markus 8:1-10).

Dalam Alkitab memang dituturkan bahwa, Yesus tidak pernah menyuruh para muridNya melakukan apa yang Dia sendiri tidak terlebih dahulu lakukan. Dia yang melalui hidupNya sangat memuliakan kemanusiaan sehinga kita bisa mengenal dalam diriNya keilahian itu, mendemonstrasikan diriNya sebagai pribadi yang peka terhadap pergumulan manusia, serta selalu siap sedia untuk menolong sesama. Melalui pelayananNya dan pendamaianNya, Yesus membagi-bagikan kasihNya kepada sesamaNya, dengan jalan pengosongan diri atau pembatasan diri. Pola hidup yang siap untuk menaruh batas bagi diri dan keinginan pribadi, demi terbuka ruang bagi orang lain,untuk menyatakan keinginan dan memperoleh kenyamanan, patut menjadi komitmen agama. Menjalani hidup dalam kasih seperti ini, baik kepada Tuhan, sesama, dan alam, sangat berpotensi meminimalisir bahkan juga mengakhiri segala bentuk ketamakan, persoalan, pertikaian, bahkan bencana dan malapetaka. Kesadaran untuk memetik bekal hidup untuk hidup secukupnya, dari kekayaan alam yang diperuntukkan sebagai bekal hidup untuk semua makhluk, agar semua makhluk bisa hidup cukup, adalah sebuah tindakan spiritualitas yang sangat menginspirasi dan mentransformasi umat beragama. 


\section{Penutup.}

Alkitab menyaksikan bahwa Tuhan melalui karya penyelamatanNya membangun persekutuan keselamatan, yakni persekutuan orang orang yang berbagi makanan diantara mereka. Bertolak dari keyakinan ini bahwa kita percaya kepada dunia surgawi dimana semua manusia akan ambil bagian, dalam jamuan makan bersama dihadapan Tuhan, maka kita tergerak untuk belajar mewujudkan dunia surgawi itu di sini dan kini. Dalam jamuan keselamatan Allah, semua orang bukan sebagai orang kaya atau orang miskin, orang asing atau pendatang, melainkan sebagai sesama anggota dalam keluarga Allah.Kritik Karl Marx terhadap agama bahwa agama itu sebagai produks alienasi sangat konstruktif. Kritik itu menyadarkan agama bahwa misinya di dunia ini, adalah menghadirkan apa yang diyakininya dan mengerjakan apa yang dia doakan " datanglah kerajaanMu di bumi “.

"SIAPA BERDOA DIA AKAN BERDIRI DI PIHAK KORBAN, BUKAN DI PIHAK PEMENANG “ (JOHAN BAPTIST METZ). 
Membedah Masalah Kemiskinan Ekonomi Di Indonesia Da $r$ i Perspektif Karl Marx Tentan Agama Sebagai Produks Alienasi | 57

\section{BIBLIOGRAFI}

Baun, Gregory. Religion and Alienation. New York: Paulist Press, 1975.

Choromaster. NKRI HARGA MATI. Yogyakarta: Penerbit Samudra Biru, 2012.

Darma Putra, I Nyoman. BALI Menuju Jagaditha: Aneka Perspektif. Denpasar: Bali Pustaka Post, 2004.

Murtiningsih, Wahyu. Para Filsuf dari Plato sampai Ibnu Bajjah. Yogyakarta: IrCiSoD, 2012.

Takdir Ilahi, Mohammad. Nasionalisme Dalam Bingkai Pluralitas Bangsa, Paradigma Pembangunan \& Kemandirian Bangsa. Yogyakarta: AR-RUZZ MEDIA, 2012. 
58|Jurnal Teologi S A C T UM DOMINE 